\title{
PROFIL TEKANAN DARAH ANGGOTA KELOMPOK SENAM LANSIA CONDONG CATUR, DEPOK, SLEMAN, DAERAH ISTIMEWA YOGYAKARTA
}

\author{
Oleh: \\ Prijo Sudibjo, Jaka Sunardi, dan Rachmah Laksmi Ambardini \\ Dosen Jurusan Pendidikan Kesehatan dan Rekreasi FIK UNY
}

\section{Abstrak}

Tekanan darah seseorang akan semakin bertambah dengan bertambahnya usia. Tekanan darah tinggi pada usia lanjut usia (lansia) berkaitan erat dengan timbulnya penyakit jantung, ginjal, stroke dan penyakit pembuluh darah yang lainnya. Latihan fisik yang teratur merupakan salah satu upaya untuk membantu menurunkan level tekanan darah pada lansia. Tujuan penelitian ini adalah untuk mengetahui gambaran level tekanan darah kelompok senam lansia dan untuk mengetahui efek senam lansia terhadap tekanan darah kelompok senam lansia.

Penelitian ini merupakan penelitian deskriptif cross sectional pada seluruh anggota kelompok senam lansia Paguyuban Lansia Mina Makarti, Condong Catur, Depok, Sleman Daerah Istimewa Yogyakarta. Pengambilan subjek penelitian dilakukan secara purposive sampling. Semua subjek diukur tekanan darah dan denyut nadi. Tekanan darah diukur dengan sphygmomanometer air raksa untuk mengetahui tekanan sistolik dan diastolik. Selain itu pada setiap subjek dicari beberapa faktor risiko terhadap terjadinya tekanan darah tinggi, penyakit akibat tekanan darah tinggi, sindroma metabolik serta lamanya mengikuti senam lansia. Data akan ditampilkan secara diskriptif kualitatif dengan persentase.

Hasil penelitian menunjukkan bahwa dari semua subjek penelitian yang mempunyai tekanan darah normal hanya terdapat 8 orang anggota saja atau sekitar 13,1 $\%$, sedangkan sisanya sebesar 53 orang 86,9 \% mengindikasikan adanya hipertensi. Hipertensi meliputi prehipertensi 17 orang 27,9 \%, hipertensi stage 1 ditemukan 20 orang 32,8 \%, dan hipertensi stage 2 sebanyak 16 orang 26,2 \%, namun sebagian besar subjek yang terindikasi hipertensi kurang menyadarinya. Selain itu ditemukan pula adanya beberapa faktor risiko lain seperti peningkatan timbunan lemak sentral, indeks massa tubuh (IMT) yang tinggi yang akan mengakibatkan tingginya penyakit cardiovasculare dan sindrom metabolik. Tingginya kasus hipertensi, tingginya timbunan lemak sentral, dan IMT mengindikasikan bahwa efek senam yang diharapkan masih belum bisa dirasakan.

Kata Kunci: tekanan darah, tekanan darah tinggi, lansia

Menurut Departemen Kesehatan Republik Indonesia (RI) yang disebut usia lansia adalah usia 65 tahun ke atas, sedangkan menurut organisasi kesehatan dunia WHO yang disebut usia lansia adalah usia 60 tahun ke atas. Pada usia ini sangatlah rentan terhadap kejadian tekanan darah tinggi atau hipertensi. Dengan bertambahnya usia akan terjadi peningkatan tekanan darah baik sistolik maupun diastolik. Beberapa penelitian menunjukkan bahwa hipertensi pada lansia berkaitan erat dengan jenis kelamin, bertambahnya umur seseorang, kebiasaan merokok, kebiasaan konsumsi garam yang berlebihan, hiperlipidemia, diabetes melitus, 
obesitas, faktor psikologis, dan kurangnya aktivitas fisik seseorang. Data epidemiologis di Amerika dan Eropa menunjukkan bahwa prevalensi tekanan darah tinggi pada usia lansia berkisar antara $53 \%$ dan $72 \%$ (Babatsikou and Zavitsanau, 2010: 25).

Tekanan darah tinggi pada lansia berkaitan erat dengan timbulnya penyakit jantung, ginjal, stroke, dan penyakit pembuluh darah yang lainnya. Modifikasi gaya hidup dengan melakukan latihan fisik terbukti banyak bermanfaat bagi penderita hipertensi dalam membantu menurunkan tekanan darah. Latihan fisik yang dilakukan terutama adalah latihan fisik aerobik dan atau dapat dikombinasikan dengan latihan beban. Latihan fisik yang teratur merupakan salah satu upaya untuk membantu menurunkan level tekanan darah pada lansia.

Latihan fisik merupakan bentuk aktivitas fisik yang terencana, terstruktur, terukur, dan progresif yang melibatkan gerakan tubuh (otot-otot tubuh) berulang-ulang dan dikerjakan dengan maksud untuk mendapatkan peningkatan kebugaran jasmani. Dalam melakukan latihan fisik harus dipenuhi beberapa sarat dalam frekuensi, intensitas, durasi, dan jenis latihan yang dilakukan agar memperoleh hasil seperti yang diharapkan. Telah diketahui bahwa latihan fisik dapat mencegah, mengobati, serta mengontrol terjadinya hipertensi.

Penderita hipertensi yang mendapatkan obat-obatan antihipertensi dapat melakukan aktivitas fisik aerobik, bahkan latihan fisik yang bersifat kompetisi, namun perlu dilakukan pemeriksaan dan monitoring ketat oleh tenaga profesional. Penggunaan obat-obatan antihipertensi perlu mendapat perhatian karena selain dapat menurunkan tekanan darah, obatobatan tersebut juga dapat menurunkan penampilan (exersise performance). Dengan demikian latihan fisik diharapkan dapat membantu mencegah terjadinya komplikasi akibat tekanan darah tinggi yang sering dialami oleh kelompok umur lansia. Selama ini belum tersedia data tentang level tekanan darah pada kelompok senam lansia yang sangat diperlukan dalam mengetahui profil tekanan darah pada kelompok lansia yang secara teratur melakukan aktivitas fisik senam lansia, serta untuk mengetahui manfaat senam lansia pada kelompok lansia untuk membantu menstabilkan tekanan darah.

\section{KAJIAN PUSTAKA}

\section{Lansia}

Menurut Undang-Undang Republik Indonesia Nomor 13 Tahun 1998 yang dimaksud dengan lansia adalah seseorang yang telah mencapai usia 60 tahun ke atas. Keberhasila pembangunan di berbagai bidang terutama bidang kesehatan menye-babkan terjadinya peningkatan usia harapan hidup (UHH) penduduk dunia termasuk Indonesia. Namun di balik keberhasilan peningkatan UHH terselip tantangan yang harus diwaspadai, yaitu ke depannya Indonesia akan menghadapi beban tiga (triple burden) yaitu di samping 
meningkatnya angka kelahiran dan beban penyakit (menular dan tidak menular), juga akan terjadi peningkatan angka beban tanggungan penduduk kelompok usia produktif terhadap kelompok usiatidak produktif. Ditinjau dari aspek kesehatan, kelompok lansiaakan mengalami penurunan derajat kesehatan baik secara alamiah maupun akibat penyakit (Pusat Data dan Informasi Kementrian Kesehatan RI, 2014: 2-3).

Organisasi kesehatan dunia WHO mengklasifikasikan lansia menjadi beberapa tahapan yaitu usia pertengahan (middle age) 45-59 tahun, lansia (elderly) 60-74 tahun, lanjut usia tua (old) 75-90 tahun dan usia sangat tua (very old) di atas 90 tahun. Sedangkan Departemen Kesehatan RI tahun 2009 mengklasifikasikan kelompok umur 46-55 tahun sebagai masa lansia awal, umur 56-65 tahun sebagai masa lansia akhir, dan lebih dari 65 tahun sebagai masa manula. Pada lansia sudah terjadi kemunduran fungsi sel dan jaringan tubuh sehingga pada lansia semakin rentan terhadap terjadinya penyakit bahkan dapat menimbulkan kematian.

\section{Hipertensi (Tekanan Darah Tinggi)}

Tekanan darah seseorang menggambarkan seberapa besar tekanan dalam pembuluh darah yang dihasilkan dari besar kecilnya tekanan pemompaan oleh jantung maupun besar kecilnya tekanan di dinding pembuluh darah itu sendiri. Pengukuran tekanan darah nanti akan menggambarkan besarnya sistolik dan diastolik. Tekanan sistolik menggambarkan tekanan darah saat jantung memompa darah keluar sedangkan diastolik menggambarkan tekanan darah saat jantung dalam kondisi relaksasi.

Kelly and Kelly (2001: 299) mengatakan bahwa tekanan darah seseorang akan cenderung meningkat dengan bertambahnya umur seseorang. Kriteria hipertensi atau tekanan darah tinggi berbeda-beda dari waktu ke waktu. The Seventh Report of The Joint National Committe mengklasifikasikan tekanan darah tinggi serta penatalaksanaannya pada kelompok umur 18 tahun ke atas seperti tampak pada Tabel 1. 


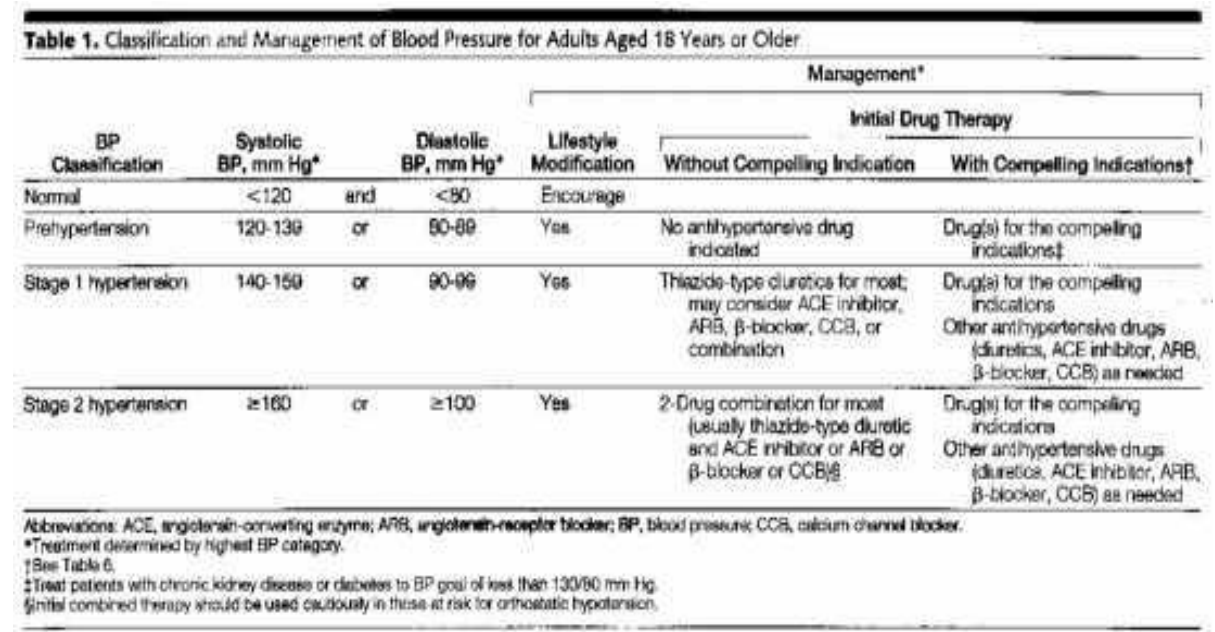

Menurut Zanabria dan Welch (2003: 1), hipertensi dikelompokkan menjadi dua bagian besar yaitu hipertensi essensial yang tidak diketahui penyebabnya dan hipertensi sekunder yang disebabkan oleh adanya penyakit lain. Hipertensi sering terjadi pada usia pertengahan dan usia tua, laki-laki lebih sering terjadi daripada perempuan. Studi epidemiologik menunjukkan bahwa hipertensi berhubungan dengan rendahnya tingkat kebugaran fisik seseorang dan obesitas. Hipertensi juga merupakan faktor risiko terhadap terjadinya stroke, infark myocard, penyakit jantung, dan gagal ginjal kronis. Hipertensi dapat terjadi akibat peningkatan tekanan darah sistolik, diastolik, atau keduanya. Seseorang yang mempunyai tekanan darah lebih dari 160/95 mmHg mempunyai risiko sebesar 150-300 \% untuk terjadinya penyakit jantung koroner (coronary heart disease), gagal jantung kronik (chronic heart disease), claudicatio intermitent, dan stroke dibandingkan dengan orang normal atau normotensi (Zanabria dan Welch, 2003: 1). Pescatello et.al. (2004: 550) juga mengatakan bahwa hipertensi merupakan gangguan kesehatan utama yang berhubungan dengan peningkatan insidensi kematian akibat penyakit kardiovaskuler. Tekanan darah istirahat, riwayat keluarga hipertensi, indeks massa tubuh, tingkat kebugaran dan aktivitas tubuh, serta respons tubuh yang berlebihan selama dan atau setelah melakukan latihan fisik adalah sesuatu yang dipercaya dapat dipergunakan untuk memprediksi apakah seorang individu akan menderita hipertensi di kemudian hari (Pescatello et.al., 2004: 550).

\section{Latihan Fisik}

Banyak anggapan dalam masyarakat bahwa melakukan aktivitas fisik rutin sehari-hari seperti pekerjaan rumah tangga atau bekerja secara fisik merupakan aktivitas olahraga. Meskipun aktivitas fisik yang dilakukan sehari-hari terbukti bermanfaat terhadap kesehatan, namun pengertiannya sangat berbeda dengan olahraga (yang selanjutnya disebut sebagai 
latihan fisik). Bergerak atau melakukan aktivitas fisik di sini berarti melakukan setiap gerakan tubuh yang dapat meningkatkan pengeluaran energi. Hal ini berbeda dengan latihan fisik karena latihan fisik dalam pengertiannya merupakan bentuk aktivitas fisik yang terencana, terstruktur, terukur, dan progresif yang melibatkan gerakan tubuh (terutama otototot besar) berulang-ulang dan dilakukan dengan maksud untuk mendapatkan peningkatan kebugaran jasmani. Adapun komponen kebugaran jasmani dapat meliputi beberapa hal seperti komposisi tubuh, kelenturan/fleksibilitas tubuh, kekuatan otot, daya tahan jantung dan paru, serta daya tahan otot (Karim, 2001:5).

Latihan fisik yang dilakukan dapat mempunyai beberapa tujuan yaitu sebagai upaya rekreasi, membina kesehatan, membina serta meningkatkan kesegaran jasmani, dan sebagai upaya untuk mencapai prestasi puncak (Adiputra, 2008: 1). Latihan fisik yang lebih utama yang sering dilakukan untuk menjaga kebugaran adalah latihan fisik yang bersifat aerobik yang melibatkan gerakan pada seluruh otot badan terutama otot-otot besar. Latihan fisik aerobik ini membantu dalam pencapaian kebugaran jantung dan paru sehingga akan memperbaiki pula sistem jantung dan pembuluh darah serta sistem pernafasan. Latihan aerobik harus dilakukan secara terencana, terstruktur, terukur dan terprogram yang meliputi komponen frekuensi latihan, intensitas latihan, durasi latihan, serta jenis latihan yang akan dilakukan. Komponen-komponen tersebut harus disesuaikan dengan target/tujuan latihan agar latihan yang dilakukan dapat memperoleh hasil seperti yang diinginkan.

Frekuensi latihan menunjukkan berapa kali latihan dilakukan dalam seminggu. Durasi latihan menunjukkan lama latihan yang dilakukan setiap sesi latihan. Intensitas latihan menunjukkan seberapa berat latihan dilakukan. Secara praktis intensitas latihan dapat diukur berdasarkan persentase dari frekuensi denyut jantung maksimal atau maximal heart rate (MHR). Menurut Nazario, 2004: 2 Frekuensi denyut jantung maksimal dapat dihitung dengan rumus sederhana sebagai berikut:

\section{jantung maksimal = 220 - umur dalam tahun.}

Berdasarkan MHR yang dicapai, intensitas latihan aerobik dapat dibagi menjadi intensitas ringan (35-59 \% MHR), intensitas sedang (60-79\% MHR), dan intensitas tinggi (80-89 \% MHR). Peningkatan intensitas latihan dapat dilakukan melalui penambahan beban latihan, yaitu dengan gerakan meloncat-loncat, atau dengan mempercepat frekuensi gerak. Menurut American College of Sport Medicine (ACSM) intensitas latihan aerobik harus 
mencapai target zone sebesar 60-90 \% dari frekuensi denyut jantung maksimal atau maximal heart rate (Pollock \& Wilmore, 1990: 110).

Penelitian dilakukan di kelompok senam Paguyuban Lansia Mina Makarti Condong Catur, yang aktif datang melakukan kegiatan senam dan hadir pada saat dilakukan penelitian. Dari seluruh yang hadir didapatkan sebanyak 61 orang anggota yang terdiri dari 27 orang laki-laki dan 34 orang perempuan. Semua anggota kelompok yang hadir ini diberikan penyuluhan tentang manfaat olahraga terhadap kesehatan lansia khususnya dalam membantu pencegahan dan pengobatan penyakit cardiocerebrovasculare, seperti hipertensi, sakit jantung, ginjal, dan penyakit pembuluh darah yang lainnya. Selain diberikan penyuluhan, kepada anggota kelompok yang hadir dilakukan pemeriksaan fisik sederhana dan pengukuran antropometris seperti pengukuran tinggi badan, berat badan, berat badan, dan lingkar perut. Selain itu juga dilakukan pemeriksaan laboratorium sederhana berupa pemeriksaan kadar gula darah puasa. Pemeriksaan-pemeriksaan ini bertujuan untuk memperoleh gambaran tentang kondisi kesehatan lansia anggota kelompok senam, yang berisiko terhadap terjadinya penyakit cardiocerebrovasculare dan sindrom metabolik. Dilakukan pula upaya pengumpulan data berupa faktor risiko penyakit cardiocerebrovasculare dengan memberikan beberapa pertanyaan kepada setiap anggota kelompok.

Tabel 2 menunjukkan profil tekanan darah anggota kelompok yang hadir. Data dari semua anggota kelompok menunjukkan bahwa tensi normal hanya terdapat pada 8 orang anggota saja atau sekitar 13,1 \%, sedangkan sisanya sebesar 53 orang $(86,9 \%)$ mengindikasikan adanya hipertensi. Hipertensi meliputi prehipertensi sebanyak 17 orang $(27,9 \%)$, hipertensi stage 1 sebanyak 20 orang (32,8 \%), dan hipertensi stage 2 sebanyak 16 orang $(26,2 \%)$ pada gambar 1.

Tabel 2. Klasifikasi Tekanan Darah Kelompok Senam Laki-laki dan Perempuan.

\begin{tabular}{|c|c|c|c|c|c|c|}
\hline \multirow{2}{*}{$\begin{array}{c}\text { Klasifikasi } \\
\text { TekananDarah }\end{array}$} & \multicolumn{2}{|c|}{ Laki-Laki } & \multicolumn{2}{|c|}{ Perempuan } & \multicolumn{2}{|c|}{ Jumlah Total } \\
\hline & $\mathbf{N}$ & $\%$ & $\mathbf{N}$ & $\%$ & $\mathbf{N}$ & $\%$ \\
\hline Normal & 1 & 7,3 & 7 & 20,6 & 8 & 13,1 \\
\hline Prehipertensi & 7 & 25,9 & 10 & 29,4 & 17 & 27,9 \\
\hline Hipertensi Stage 1 & 11 & 40,7 & 9 & 26,5 & 20 & 32,8 \\
\hline Hipertensi Stage 2 & 8 & 29,7 & 8 & 23,5 & 16 & 26,2 \\
\hline & 27 & 100 & 34 & 100 & 61 & 100 \\
\hline
\end{tabular}

Klasifikasi tekanan darah pada anggota kelompok laki-laki terdapat 1 orang $(3,7 \%)$ dengan tekanan darah normal dan sisanya 7 orang $(25,9 \%)$ pre hipertensi, 11 orang $(40,7 \%)$ hipertensi stage 1, dan 8 orang $(29,7 \%$ ) hipertensi stage 2 (Gambar 2). Sedangkan klasifikasi 
tekanan darah pada anggota kelompok perempuan terdapat 7 orang (20,6\%) dengan tekanan darah normal dan sisanya 10 orang $(29,4 \%)$ pre hipertensi, 9 orang $(26,5 \%)$ hipertensi stage 1, dan 8 orang $(23,5 \%)$ hipertensi stage 2.

\section{Tabel 3. Faktor Risiko Penyakit Cardiocerebrovasculare pada Anggota Kelompok Senam}

\begin{tabular}{|l|c|c|c|}
\hline \multicolumn{1}{|c|}{ Faktor Risiko } & Laki-Laki & Perempuan & Jumlah \\
\hline Hipertensi & 11 & 7 & 18 \\
Diabetes Melitus & 3 & 4 & 7 \\
Hiperkolesterolemia & 3 & 2 & 5 \\
Stroke & 0 & 2 & 2 \\
Penyakit Jantung & 3 & 2 & 5 \\
\hline
\end{tabular}

Berdasarkan hasil penelusuran faktor risiko penyakit cardiocerebrovasculare yang lain, didapatkan hasil seperti pada Tabel 3. Dari penelusuran yang didapat dari wawancara diperoleh hasil bahwa anggota kelompok yang mempunyai riwayat sakit darah tinggi (hipertensi) terdapat11 orang laki-laki dan 7 orang perempuan. Faktor risiko yang lain berupa diabetes mellitus, hiperkolesterolemia, stroke, dan penyakit jantung seperti tampak pada Tabel 3. Penelitian ini juga mengukur tinggi badan dan berat badan anggota kelompok senam, yang berguna dalam menentukan IMT. Hasil penghitungan IMT dapat dilihat pada Tabel 4.

Tabel 5. Indeks Massa Tubuh (IMT) pada Semua Anggota Kelompok Senam.

\begin{tabular}{|c|c|c|c|c|c|c|c|}
\hline \multirow[t]{2}{*}{ Kategori } & \multirow{2}{*}{$\begin{array}{c}\text { Indeks } \\
\text { Massa Tubuh }\end{array}$} & \multicolumn{2}{|c|}{ Laki-Laki } & \multicolumn{2}{|c|}{ Perempuan } & \multicolumn{2}{|c|}{ Jumlah } \\
\hline & & $\mathbf{N}$ & $\%$ & $\mathbf{N}$ & $\%$ & $\mathbf{N}$ & $\%$ \\
\hline Kurus & $<18,5$ & 0 & 0 & 3 & 8,8 & 3 & 4,9 \\
\hline Normal & $18,5-22,9$ & 12 & 44,4 & 8 & 23,5 & 20 & 32,8 \\
\hline Pre Obese & $23-24,9$ & 2 & 7,5 & 8 & 23,5 & 10 & 16,4 \\
\hline Obese I & $25-29,9$ & 12 & 44,4 & 11 & 32,4 & 23 & 37,7 \\
\hline Obese II & $\geq 30$ & 1 & 3,7 & 4 & 11,8 & 5 & 8,2 \\
\hline & & 27 & 100 & 34 & 100 & 61 & 100 \\
\hline
\end{tabular}

Hasil penelitian menunjukkan bahwa secara keseluruhan, sebagian besar IMT anggota kelompok senam menunjukkan kategori Obese I sebesar $(37,7 \%)$ seperti tampak pada Gambar 4. Kategori IMT pada kelompok laki-laki sebagian besar adalah kategori normal dan Obese I atau sebesar 44,4\% (Gambar 5), sedangkan pada kelompok perempuan sebagian besar adalah kategori Obese I atau sebesar 32,4 \%.Pengukuran secara antropometris dilakukan juga untuk mengukur besaran lingkar perut, untuk mengetahui prediksi timbunan 
lemak sentral. Hasil penelitian yang didapatkan menunjukkan bahwa sebagian besar anggota senam mempunyai besaran lingkar perut yang normal baik pada laki-laki $(<90 \mathrm{~cm})$ maupun pada perempuan $(<80 \mathrm{~cm})$ atau total sebesar 55,7 \% (Tabel 5).

Tabel 6. Ukuran Lingkar Perut Seluruh Anggota Kelompok Senam

\begin{tabular}{|l|c|c|c|c|c|c|}
\hline \multirow{2}{*}{$\begin{array}{c}\text { Ukuran Lingkar } \\
\text { Perut }\end{array}$} & \multicolumn{2}{|c|}{ Laki-Laki } & \multicolumn{2}{c|}{ Perempuan } & \multicolumn{2}{c|}{ Jumlah } \\
\cline { 2 - 7 } & $\mathbf{N}$ & \% & N & \% & N & \% \\
\hline Normal & 22 & 81,5 & 12 & 35,3 & 34 & 55,7 \\
Meningkat & 5 & 18,5 & 22 & 64,7 & 27 & 44,3 \\
\hline
\end{tabular}

Pemeriksaan kadar gula darah puasa dilakukan pada semua sampel penelitian seperti tampak pada Table 6. Pemeriksaan gula darah puasa menunjukkan bahwa sebagian besar anggota kelompok senam mempunyai kadar gula darah puasa yang normal sebesar 63,9 \%, baik pada laki-laki (59,3\%) maupun pada perempuan $(67,7 \%)$. Namun demikian persentase abnormalitas nilai kadar gula darah puasa pada laki-laki sedikit lebih tinggi dibandingkan dengan perempuan.

Tabel 6. Kadar Gula Darah Puasa Seluruh Anggota Kelompok Senam

\begin{tabular}{|l|c|c|c|c|c|c|}
\hline \multirow{2}{*}{$\begin{array}{c}\text { Kadar } \\
\text { GulaDarahPuasa }\end{array}$} & \multicolumn{2}{|c|}{ Laki-Laki } & \multicolumn{2}{c|}{ Perempuan } & \multicolumn{2}{c|}{ Jumlah } \\
\cline { 2 - 7 } & $\mathbf{N}$ & $\mathbf{\%}$ & $\mathbf{N}$ & $\mathbf{\%}$ & $\mathbf{N}$ & $\%$ \\
\hline Normal & 16 & 59,3 & 23 & 67,7 & 39 & 63,9 \\
Tinggi & 11 & 40,7 & 11 & 32,3 & 22 & 36,1 \\
\hline
\end{tabular}

\section{PEMBAHASAN}

Lansia identik dengan menurunnya daya tahan tubuh dan mengalami berbagai macam penyakit. Lansia akan memerlukan obat yang jumlah atau macamnya pergantung pada penyakit yang diderita. Telah diketahui bahwa dengan bertambahnya usia akan terjadi pula peningkatan tekanan darah sistolik maupun diastolik (Kelly and Kelly, 2001: 300). Tekanan darah sistolik akan terus meningkat hingga usia dewasa yang terjadi karena adanya progresivitas kekakuan pembuluh darah seiring dengan bertambahnya usia, sedangkan tekanan darah diastolik cenderung menetap hingga dekade keenam baru kemudian akan menurun (Pescatello et.al., 2004: 533).

Latihan fisik terutama latihan aerobik dapat mencegah perkembangan hipertensi dan menurunkan tekanan darah pada individu dewasa dengan normotensi ataupun hipertensi. Untuk itu dianjurkan adanya modifikasi gaya hidup dengan melakukan program latihan fisik 
sebagai upaya pencegahan, pengobatan, dan pengawasan hipertensi (Pescatello et.al., 2004: 535). Hasil penelitian menunjukkan bahwa sebagian besar subjek penelitian atau sebesar 53 orang $(86,9 \%)$ mengindikasikan adanya hipertensi yang meliputi prehipertensi sebanyak 17 orang $(27,9 \%)$, hipertensi stage 1 sebanyak 20 orang $(32,8 \%)$, dan hipertensi stage 2 sebanyak 16 orang $(26,2 \%)$.

Menurut JNC 7 kelompok prehipertensi masih belum memerlukan pengobatan, namun hanya memerlukan perubahan gaya hidup. Adapun perubahan gaya hidup di sini berupa penurunan berat badan, pengaturan pola makan, mengurangi asupan garam, dan aktivitas fisik seperti olahraga. Untuk itu dianjurkan adanya modifikasi gaya hidup dengan melakukan program latihan fisik sebagai upaya pencegahan, pengobatan, dan pengawasan hipertensi. Latihan fisik terutama latihan aerobik dapat mencegah perkembangan hipertensi dan menurunkan tekanan darah pada individu dewasa dengan normotensi ataupun hipertensi. Namun demikian agar dapat membantu dalam pengontrolan tekanan darah, perubahan gaya hidup tidak hanya dengan melakukan aktivitas fisik atau olahraga saja, tetapi harus diimbangi pula dengan upaya menurunkan berat badan, pengaturan pola makan, serta mengurangi asupan garam (Chobanian et.al., 2003: 2545).

Masih tingginya angka kejadian hipertensi di sini mengindikasikan bahwa efek latihan yang diharapkan masih belum cukup untuk membantu menurunkan tekanan darah. Hal ini kemungkinan disebabkan oleh masih kurangnya kesungguhan subjek dalam mengikuti aktivitas senam, atau frekwensi latihan per minggu masih belum cukup. Pescatello et.al. (2004) mengatakan bahwa frekuensi latihan dan intensitas latihan fisik yang dilakukan berbanding terbalik dengan risiko terjadinya hipertensi di kemudian hari. Ada beberapa faktor risiko hipertensi dan penyakit akibat hipertensi yang dapat meningkatkan kejadian penyakit cerebrovasculare seperti hiperkolesterolemia, stroke, penyakit jantung, serta diabetes, namun jumlahnya sangat sedikit.

Indeks massa tubuh menggambarkan kelebihan jaringan lemak di seluruh tubuh yang dapat dihitung dengan membagi berat badan dalam kilogram $(\mathrm{kg})$ dengan tinggi badan dalam meter pangkat dua (m2). Dengan sendirinya IMT yang abnormal berbeda antara bangsa/ras, misalnya IMT yang normal untuk Eropa belum tentu sama dengan orang Asia yang umumnya lebih kecil. Oleh karena itu, pada tahun 2000 World Health Organization (WHO) membuat kriteria IMT yang berbeda dan lebih sesuai untuk orang Asia dari kriteria semula sesuai untuk orang Eropa dan Amerika Serikat. 
Tabel 7. Klasifikasi Berat Badan berdasarkan IMT untuk Orang Asia

\begin{tabular}{|l|l|l|}
\hline \multicolumn{1}{|c|}{ Klasifikasi } & \multicolumn{1}{|c|}{ IMT $\left(\mathrm{kg} / \mathrm{m}^{2}\right)$} & \multicolumn{1}{c|}{ Risiko morbiditas } \\
\hline Kurus & $<18.5$ & Rendah \\
Normal & $18.5-22.9$ & Seding \\
Kegenmikan & $\geq 23$ & \\
Pra-obes & $23-24.9$ & Meningkat \\
Obes I & $25-29.9$ & Seding \\
Obes II & $\geq 30$ & Berat \\
\hline
\end{tabular}

The Asia-Pacific perspective: Redefining obesity and its treatment. Wotid Health Organization Collaborating Centre for the Epidemiology of Diabetes Mellinas and Health Promotion for Nonconmunicable Disease. Melbourne $2000^{\text {? }}$

Hasil penelitian menunjukkan bahwa, secara keseluruhan sebagian besar IMT anggota kelompok senam menunjukkan kategori Obese I sebesar (37,7 \%) seperti tampak pada Gambar 4. Kategori IMT pada kelompok laki-laki sebagian besar adalah kategori normal dan Obese I atau sebesar 44,4 \%, sedangkan pada kelompok perempuan sebagian besar adalah kategori Obese I atau sebesar 32,4 \%. Kondisi ini menunjukkan bahwa pada sebagian besar anggota kelompok senam lansia mempunyai timbunan lemak yang cukup tinggi di badannya. Hasil ini dapat memberikan gambaran bahwa masih tingginya angka tekanan darah tinggi pada kelompok senam lansia ini kemungkinan disebabkan olehlatihan fisik yang dilakukan tidak diimbangi dengan pengaturan pola makan, mengurangi asupan garam, dan upaya penurunan berat badan.

\section{KESIMPULAN}

Berdasarkan data yang diperoleh dari penelitian yang dilakukan menunjukkan bahwa sebagian besar anggota senam lansia mempunyai tekanan darah yang tinggi (hipertensi), dan tingginya timbunan lemak sentral dan IMT. Selain itu tingginya kasus hipertensi dan tingginya timbunan lemak sentral dan IMT mengindikasikan bahwa efek senam yang diharapkan masih belum bisa dirasakan. Untuk itu hendaknya senam lansia dilakukan dengan frekuensi, intensitas, durasi latihan yang cukup dilakukan secara teratur, berkesinambungan, dan terprogram agar diperoleh manfaat dari senam lansia. Selain itu juga perlu dilakukan upaya perubahan gaya hidup lain seperti upaya penurunan berat badan, pengaturan pola makan, dan membatasi asupan garam selain melakukan latihan fisik seperti senam. Hal ini perlu dilakukan karena masih tingginya kasus hipertensi pada anggota kelompok senam lansia. 


\section{DAFTAR PUSTAKA}

Adiputra, N., (2008). Kesehatan Olahraga. Denpasar: Fakultas Kedokteran Universitas.

Babatsikou, F. \& Zavitsanau, A. (2010). Epidemiology of Hypertension in The Elderly, Health Science Journal, volume 4 issue 1 pp. 24-30.

Chobanian, A.V., Bakris, G.L., Black, H.R., Sushman, W.C., Green, L.A., Izzo, J.I., Jones, D.W., Materson, B.J., Oparil, S., Wright, J.T., Roccella, E.J., and National High Blood Pressure Education Program Coordinating Committee.(2003). The Seventh Report of The Joint National Committe on Prevention, Detection, Evaluation, and Treatment on High Blood Pressure, The JNC 7 Report, JAMA, vol 289 no 11 pp 253473.

Karim, F.( 2001). Pendidikan Kesehatan Olahraga Bagi Petugas Kesehatan. Jakarta: Direktur Kesehatan Komunitas.

Kelley, G.A., \& Kelley, K.S., 2001, Aerobic Exercise and Resting Blood Pressure in Older Adults: A Meta-analytic Review of Randomized Controlled Trials, Journals of Gerontology: MEDICAL SCIENCES, vol 56 A no 5, pp M298-M303.

Nazario, B. (2004). New Guidelines for Exercise and Hypertension. http://www.webmd.com/hypertension-high-blood-pressure/news/20040309/newsguidelines-exercise-hypertension

Pescatello, L.S., Franklin B.A., Fagard, R., Farquhar W.B., Kelley, G.A., and Ray, C.A., (2004). Execrise and Hypertension, American College of Sports Medicine, Medicine and Science in Sports and Exercise, pp. 533-553

Pollock, M.L. \& Wilmore, J.H. (1990). Exercise in Health and Disease: Evaluation and Prescription for Prevention and Rehabilitation. 2nd. Ed. Philadelphia: Saunders.

Zanabria, E, \& Welch, G.L.(2003). Hypertension and exercise. Diakses Dalam http://findarticles.com/p/articles/mi_m0675/is_2_21/ai_112982372/ 
